Inpatient Detoxification

Hogan, Lee; Jabeen, Qamar; Race, Julian; Rettie, Hannah

\title{
Alcoholism Treatment Quarterly
}

DOI:

10.1080/07347324.2018.1424591

Published: 01/10/2018

Peer reviewed version

Cyswllt i'r cyhoeddiad / Link to publication

Dyfyniad o'r fersiwn a gyhoeddwyd / Citation for published version (APA):

Hogan, L., Jabeen, Q., Race, J., \& Rettie, H. (2018). Inpatient Detoxification: Examining Factors Leading to Early Discharge. Alcoholism Treatment Quarterly, 36(3), 366-372.

https://doi.org/10.1080/07347324.2018.1424591

\section{Hawliau Cyffredinol / General rights}

Copyright and moral rights for the publications made accessible in the public portal are retained by the authors and/or other copyright owners and it is a condition of accessing publications that users recognise and abide by the legal requirements associated with these rights.

- Users may download and print one copy of any publication from the public portal for the purpose of private study or research.

- You may not further distribute the material or use it for any profit-making activity or commercial gain

- You may freely distribute the URL identifying the publication in the public portal ?

Take down policy

If you believe that this document breaches copyright please contact us providing details, and we will remove access to the work immediately and investigate your claim. 


\begin{abstract}
This study aimed to explore the factors that contributed to patients' failure to complete inpatient detoxification for drug and/or alcohol dependence. A review of case files at a 25-bedded detoxification unit in UK was undertaken. During a 12-month period $N=503$ patients accessed treatment. Treatment was predominantly offered to patients with alcohol-related problems (66\%), patients with drug-related problems (22\%) and patients with both drug and alcoholrelated problems (12\%). The mean length of treatment was two weeks. Just over half of the sample had a previous criminal conviction, with $24 \%$ of all offences being for violence. From the total admissions $n=35(7 \%)$ breached the unit rules and $n=48(10 \%)$ left treatment early against medical advice. Patients who breached unit rules were typically undertaking drug detoxification, they had poorer pre-admission preparation, and they had poor engagement in the therapeutic programme. A high-risk time for breach was on the weekend, where the most commonly cited reason was illicit substance use. Patients who left treatment against medical advice typically had an admission for drug or drug/alcohol detoxification, lived closer to the unit, had previous criminal convictions and had lower treatment engagement.
\end{abstract}

\title{
Introduction
}

Substance addiction has direct harms for substance abusers, their families and wider society. The provision of detoxification is a cost-effective way of reducing this burden (Raistrick, Heather, \& Godfrey, 2006). Where patients have complex presentations a hospital-based detoxification, as opposed to community-based one, is often advised. For example, inpatient detoxification is recommended for those who have physical health problems such as epilepsy, are malnourished, have a history of previous complicated withdrawals, psychiatric illness, multiple substance misuse, are at risk of suicide, or have had previous failed home (community-based) detoxifications (Clinical Guidelines on Drug Misuse and Dependence Update 2017 Independent Expert Working Group, 2017; FreyerAdam, Gaertner, Rumpf, John, \& Hapke, 2010). It is estimated that the cost of inpatient detoxification is more than 20 times that of a community-based one (Gossop \& Strang, 2000) and access to such services is limited (Best, O'Grady, Charalampous, \& Gordon, 2005).

Given the cost implications and limited access to inpatient detoxification, it is crucial to ensure that service users complete their treatment episode. Despite continuous improvements in treatment services, the rate of relapse postdetoxification remains between 60-90\% (Aguiar, Neto, Lambaz, Chick, \& Ferrinho, 2012; Becker, 2008; Raistrick, 2006; Spada, Nuamah, Luty, \& Nikcevic, 2008). It is currently unclear how many individuals fail to complete hospitalbased detoxification or the factors that might be associated with treatment failure. Previous literature has identified that an individual's cravings, motivation, and distress tolerance, and their ability to connect to staff along with the activity provision can all impact treatment completion rates in longer residential treatments (Daughters et al., 2005; Nordheim, Walderhaug, Alstadius, \& Kern-Godal, 2016; Palmer, Murphy, Piselli, \& Ball, 2009). Factors associated 
with early discharge from shorter, inpatient detoxification, has not been explored. The purpose of this report is to determine the various factors that are associated with patients who (a) breach the unit rules and are subsequently discharged from treatment and (b) choose to leave prior to treatment completion at a 25-bedded specialist detoxification unit in the United Kingdom.

\section{Methods}

A retrospective review of all case notes were accessed for the $\underline{n}=503$ patients who presented for inpatient detoxification from July 2013 to July 2014. Each case file was examined by hand, and a pre-determined checklist was used to identify the required information to be inputted onto a computerized database. Patient discharge outcomes were categorised as: (a) "Planned" if patients successfully reached a predetermined treatment outcome and were discharged as planned; (b) "AMA" if patients discharged themselves prior to their pre-planned treatment targets and Against Medical Advice (AMA); and (c) "Breach" if patients breached the unit rules (e.g., they used illicit drugs or alcohol on the unit, they were violent or aggressive to others) and were discharged.

A total of $N=503$ service users attended treatment at the detoxification unit over a 12-month period. The sample comprised $n=341$ males (68\%) and $n=162$ females $(32 \%)$. The mean age of the sample was 43.5-years-old ( $\underline{\mathrm{sd}}=9.7)$ and service users' age ranged from 21- to 79-years-old. The largest proportion of service users (66\%) presented with primary alcohol-related problems, $22 \%$ with primary drug-related problems, and $12 \%$ with both alcohol- and drug-related problems. The reason for referral in the majority of cases was for detoxification (97\%), with a small proportion undertaking stabilization (2\%) and an even smaller proportion undertaking a reduction in their prescribed medication(s) (1\%). For those with primary alcohol-related problems the expected length of stay was 12.0 days $(S D=4.0)$ with the actual length of stay at 11.4 days $(S D=$ 4.6); for those with primary drug-related problems the expected length of stay was 18.3 days $(S D=6.0)$ with the actual length of stay at 13.3 days $(S D=6.5)$; for those with both alcohol- and drug-related problems the expected length of stay was 18.7 days $(S D=7.4)$ with the actual length of stay at 14.2 days $(S D=8.2)$.

A total of $n=410(81 \%)$ service users had a planned discharge, $n=48(10 \%)$ left Against Medical Advice (AMA) and $n=35$ (7\%) were discharged for a breach of rules (breach). The treatment outcome of the other $n=10(2 \%)$ service users comprised one death and some missing data.

\section{Results}

Numerous analyses such as chi-square tests of independence were conducted to determine which of the factors were related to treatment outcome. A number of these factors showed no significant relationships. For example, it was suspected that a higher risk assessment score would be associated with a negative treatment outcome, yet no relationship was found in the data for self-neglect scores $\left(\mathrm{X}^{2}(6, N=484)=4.78, p=.574\right)$ suicide $\operatorname{scores}\left(\mathrm{X}^{2}(6, N=484)=4.82, p=\right.$ $.777)$ and violence scores $\left(\mathrm{X}^{2}(6, N=484)=12.44, p=.053\right)$. Treatment completion was not significantly associated with the number of previous detoxification episodes undertaken $\left(\mathrm{X}^{2}(24, N=440)=29.66, p=.196\right)$. 
Evaluation of case files indicated that early discharge from the unit (Breach or AMA) was more likely in service users admitted for drug detoxification. Patients admitted for drug detoxification accounted for $65.7 \%$ of all breaches and $43.8 \%$ of all discharges AMA; patients admitted for both drug and alcohol detoxification accounted for $22.9 \%$ of breaches and $33.3 \%$ of all discharges AMA; patients admitted for alcohol detoxification only accounted for $11.4 \%$ of breaches and $22.9 \%$ of all discharges AMA. Those service users who were admitted for drug detoxification were significantly more likely to have an early discharge before treatment completion in comparison to service users admitted for alcohol detoxification only $\left(\mathrm{X}^{2}(4, N=433)=82.12, p<.001\right)$. On average, $20.5 \%$ of drug users breached compared to $13.6 \%$ of drug and alcohol users and just $1.2 \%$ of alcohol users. This finding is consistent with Callaghan and Cunningham (2002), who reported that drug abusing service users were more likely to terminate their treatment earlier. The planned treatment completion rate was $94.5 \%$ for alcohol users, $57.6 \%$ for drug and alcohol users, and $58.0 \%$ for drug users (See Figure 1).

\section{[Insert Figure 1 Here]}

An additional variable of interest was the percentage of planned completion rates according to the distance patients resided from the hospital location. For example, it was shown that planned completion rates were lower for those patients who lived closer to the unit: Region 1 planned completion rates were $66 \%$ compared to Region 2 (73.3\%), Region 3 (77.6\%), Region 4 (82.6\%), Region $5(83.9 \%)$ and Region $6(73.7 \%)^{1}$. The implication here is that living closer to the treatment unit was associated with poorer outcomes.

Forensic history was also significantly associated with treatment outcome. If the discharge was planned, just under half (46\%) of individuals had a previous conviction, however, three quarters or more of service users who breached $(77 \%)$ or who left AMA (75\%) had a previous criminal conviction. As shown in Figure 2 (below), service users who breached or who left AMA were significantly more likely to have a conviction than not $\left(\mathrm{X}^{2}(2, N=471)=25.56, p<.001\right)$. This effect was found regardless of the service users' substance category or psychiatric health. These convictions could be anything from a driving offence to violent behaviour. More specifically, though, service users who breached (37.1\%) or left AMA (33.3\%) were significantly more likely to have a previous conviction for violence compared to service users who had a planned discharge $(21.2 \%)\left(\mathrm{X}^{2}(2, N=470)=7.33, p=.026\right)$.

$$
\text { [Insert Figure } 2 \text { Here] }
$$

\footnotetext{
${ }^{1}$ Note the unit is located within Region 1 ; Region $2=20$ miles $(32 \mathrm{~km})$ to the unit; Region $3=30$ miles $(48 \mathrm{~km})$ to the unit; Region $4=50$ miles $(80 \mathrm{~km})$ to the unit; Region $5=70$ miles $(112 \mathrm{~km})$ to the unit; \& Region $6=80$ miles $(128 \mathrm{~km})$ to the unit.
} 
Another variable associated with treatment outcome was pre-admission preparation. Significantly more people who had a planned discharge (i.e., 69\%) or left who AMA (i.e., 61\%) had pre-admission preparation compared to those who breached (e.g., with just 39\% having received pre-admission preparation), $\left(\mathrm{X}^{2}(2, N=417)=12.08, p=.002\right)$. It is unclear whether those who were most likely to breach were the people who refused to engage in pre-admission preparation or whether a lack of preparation contributed to breach; an additional plausible factor was some service users who had an emergency admission (with little or no time for pre-admission preparation) are more likely to breach. Thus, the profile of a person likely to breach unit rules is someone who refuses to participate from the start. This is supported by the group engagement of service users, with only $30 \%$ of service users who breached having good group engagement, in comparison to $47 \%$ of those who left AMA, and $87 \%$ of planned discharges $\left(\mathrm{X}^{2}(4, N=421)=84.86, p<.001\right)$.

The data further suggest that there are certain periods in the week where a discharge for a breach of rules is significantly higher. For example, 28\% of AMA discharges were over the weekend, meaning it is no more likely that an individual will leave AMA over the weekend compared to a weekday, however, $44 \%$ of breaches were over the weekend. This means service users were more likely to breach over the weekend than on a weekday.

For service users who breached, the majority either used illicit substances or tested positive on a drug test during their stay: $34 \%$ of service users tested positive for illicit drugs, $26 \%$ had consumed alcohol, and $17 \%$ were suspected to have smoked cannabis. Other less common reasons for breach included aggressive behaviour towards staff (9\%), and inappropriate behaviour such as forming relationships with other service users (11\%). For service users who left AMA, there was a wider variety of reasons cited. These included family issues (25\%), cravings and withdrawal symptoms (14\%), being unhappy with their stay $(12 \%)$, a breach of rules warning $(10 \%)$, physical health issues $(6 \%)$ and not feeling 'ready' (6\%). No reason was provided for $20 \%$ of AMA.

\section{Discussion}

This report identified that the majority of service users successfully completed treatment (i.e., 81\%), and this is particularly the case with those patients undergoing detoxification from alcohol (i.e., 94.5\%). The profile of service users who left treatment early against medical advice were those who received drugor drug/alcohol-related treatment, tended to live closer to the treatment centre, had previous criminal convictions and had lower levels of engagement in the therapeutic programme offered. It appeared that this combination of lack of engagement in the therapeutic programme and the ease of being able to return home were risk factors for early discharge. In contrast, fewer patients left against medical advice when travel to home involved a significant distance and considerable effort via public transport. Living locally to the treatment unit might also increase the availability and access to illicit substances from local connections, although this was not investigated in this report. 
The profile of service users who were discharged for breaching the unit rules were those who typically accessed treatment for drug detoxification, had a forensic history, had poor pre-admission preparation, and lacked any meaningful engagement in the psychosocial programme offered at the treatment setting. It also seemed clear that the weekend posed a risk to relapse, possibly because of cultural issues associated with the weekend (and previous use) but also as a consequence of reduced staff and activities. As weekends were associated with greater risk more diversionary activities might be necessary at these times.

Pre-detoxification preparation is a central aspect of ensuring service users are fully prepared for treatment so they can gain the most from their treatment, and is recommended in the 2017 update of the Clinical Guidelines on Drug Misuse and Dependence. Where poor engagement is a factor at the pre-admission stage of treatment, it is highly likely that service users will not engage in the broader treatment offered during their detoxification treatment. It is unclear whether those who were most likely to breach the unit rules were the people who refused to engage in pre-admission preparation or whether a lack of preparation contributed to breach.

The lack of engagement in treatment that was associated with early discharge could be driven by the need of some service users to push against boundaries or societal rules. Future research exploring reasons for early discharge by qualitatively interviewing service users could provide potential explanations for the findings from this study. Conceivably, reducing early discharge by improving methods of engagement holds the greatest promise.

\section{References}

Aguiar, P., Neto, D., Lambaz, R., Chick, J., \& Ferrinho, P. (2012). Prognostic factors during outpatient treatment for alcohol dependence: Cohort study with 6 months of treatment follow-up. Alcohol and Alcoholism, 47, 702-710. http://dx.doi.org/10.1093/alcalc/ags097

Becker, H. C. (2008). Alcohol dependence, withdrawal, and relapse. Alcohol Research and Health, 31, 348-361.

Best, D., O'Grady, A., Charalampous, I., \& Gordan D. (2005). National needs assessment for Tier 4 drugs services in England. National Treatment Agency. Retrieved from http://www.nta.nhs.uk/uploads/nta national needs assessment of tier4 drug services in england 2005 rb16.pdf

Callaghan, R.C., \& Cunningham, J. A. (2002). Gender differences in detoxification: Predictors of completion and re-admission. Journal of Substance Abuse Treatment, 23, 399-407.

Clinical Guidelines on Drug Misuse and Dependence Update 2017 Independent Expert Working Group. (2017). Drug misuse and dependence: UK guidelines on clinical management. London: Department of Health. 
Daughters, S. B., Lejuez, C. W., Bornovalova, M. A., Kahler, C. W., Strong, D. R., \& Brown, R. A. (2005). Distress tolerance as a predictor of early treatment dropout in a residential substance abuse treatment facility. Journal of Abnormal Psychology, 114(4), 729-734.

Freyer-Adam, J., Gaertner, B., Rumpf, H. J., John, U., \& Hapke, U. (2010). Alcohol dependent inpatients who receive general hospital care vs. detoxification in psychiatric care and alcohol problem 1year later. Addictive Behaviors, 35(8), 756-763.

Gossop, M., \& Strang, J. (2000). Price, cost and value of opiate detoxification treatments: Reanalysis of data from two randomised trials. British Journal of Psychiatry, 177, 262-266.

Nordheim, K., Walderhaug, E., Alstadius, S., \& Kern-Godal, A. (2016). Young adults' reasons for dropout from residential substance use disorder treatment. Qualitative Social Work, 17(1), 24-40.

Palmer, R. S., Murphy, M. K., Piselli, A. \& Ball, S. A. (2009). Substance abuse treatment drop-out from client and clinician perspectives. Substance Use Misuse, 44(7), 1021-1038.

Raistrick, D. (2006). Review of the effectiveness of treatment for alcohol problems. National Treatment Agency for Substance Misuse. Retrieved 23 August 2017 from http://www.nta.nhs.uk/uploads/nta_review_of_the_effectiveness_of_treat ment_for_alcohol_problems_fullreport_2006_alcohol2.pdf.

Spada, M. M., Nuamah, F., Luty, J., \& Nikcevic, A. V. (2008). Changes in alcohol expectancies before and after inpatient chemical detoxification for alcohol dependence. Addictive Disorders \& Their Treatment, 7, 157-161. http://dx.doi.org/10.1097/ADT.0b013e31812cb682 